\title{
A Trade-off between Maxima in Efficiency and Specific Work Output of Super- and Trans-critical $\mathrm{CO}_{2}$ Brayton Cycles
}

\author{
Pardeep Garg, Pramod Kumar* and Kandadai Srinivasan ${ }^{1}$ \\ Department of Mechanical Engineering, Indian Institute of Science, Bangalore 560 012, India
}

\begin{abstract}
Several operational aspects for thermal power plants in general are non-intuitive and involve simultaneous optimization of a number of operational parameters. In the case of solar operated power plants, it is even more difficult due to varying heat source temperatures induced by variability in insolation levels. This paper introduces a quantitative methodology for load regulation of a $\mathrm{CO}_{2}$ based Brayton cycle power plant using the 'thermal efficiency and specific work output' coordinate system. The analysis shows that a transcritical $\mathrm{CO}_{2}$ cycle offers more flexibility under part load performance than the supercritical cycle in case of non-solar power plants. However, for concentrated solar power, where efficiency is important, supercritical $\mathrm{CO}_{2}$ cycle fares better than transcritical $\mathrm{CO}_{2}$ cycle. A number of empirical equations relating heat source temperature, high side pressure with efficiency and specific work output are proposed which could assist in generating control algorithms.
\end{abstract}

Key Words: Supercritical $\mathrm{CO}_{2}$, Brayton cycles, Operational aspects, Empirical relations, Concentrated Solar Power

*Corresponding author. Fax: +91 802360 4536; email: pramod@mecheng.iisc.ernet.in

${ }^{1}$ also with Department of Mechanical Engineering, University of Western Australia, Australia. 


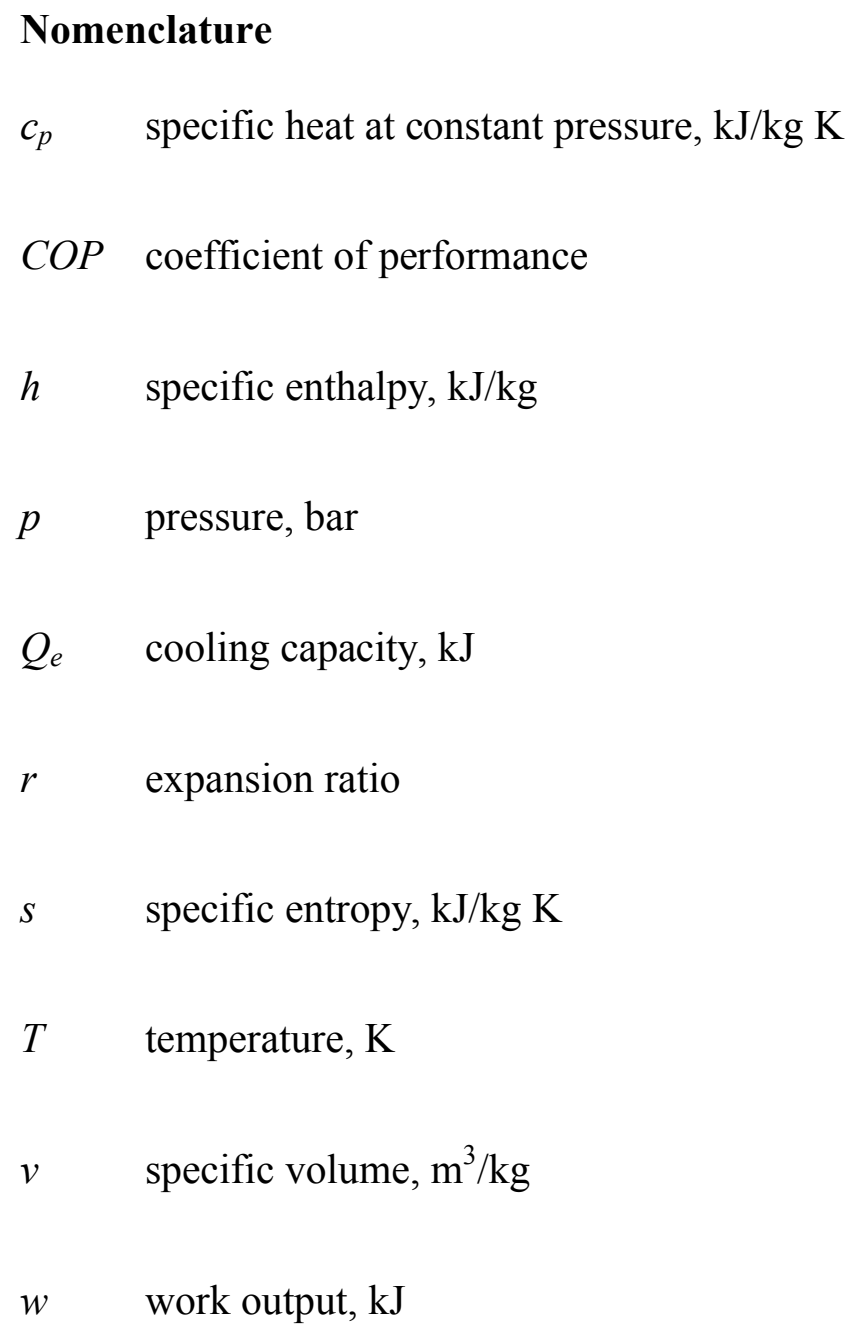


HTF heat transfer fluid

$i \quad$ inlet

$o \quad$ outlet

$S \quad$ supercritical cycle

$s p \quad$ specific

$t \quad$ turbine

TN transcritical non-condensing cycle

th thermal

1 to 6 states on ideal thermodynamic cycle

Superscript

' states on real thermodynamic cycle 


\section{INTRODUCTION}

Carbon dioxide $\left(\mathrm{CO}_{2}\right)$ based closed loop thermodynamic power cycles have acquired considerable attention for nuclear and concentrated solar power applications. Main benefits of this working fluid are high cycle efficiencies and a compact size because of small specific volumes in the usual operating limits [1]. In the case of concentrated solar power (CSP) applications, diurnal and seasonal variations in insolation levels impose special requirements for operation at maximum efficiency. Iverson et al. [2] show that thermal efficiencies fall short of predicted $50 \%$ even at turbine inlet temperatures of $600^{\circ} \mathrm{C}$ for power levels of the order of 250 kWe. They also find that the thermal inertia of the power plant allows some stable operation when the insolation levels fall and emphasize the need for control algorithms for continuous load management. For supercritical $\mathrm{CO}_{2}$ cycles, Le Roux et al. [3] proposed an optimization function based on minimization of entropy generation. They emphasize the fact that not only the global entropy reduction but also individual component entropy generation under various operating conditions, such as inlet temperature and expansion/compression ratio need to be considered in the objective function. However, Haseli [4] concludes that minimization of entropy generation in a regenerative Brayton cycle is neither equivalent to maximization of thermal efficiency nor the work output. This important outcome also summarizes the conclusions derived by other researchers [5-9]. These deductions align with the findings of Curzon and Ahlborn [10] who have shown that for a Carnot engine, the power output and the efficiency have optima at different ratios of heat sink and source temperatures. These aspects are further elucidated by Gordon and Huleihil $[11,12]$ who use the co-ordinate system of power and efficiency to bring out the universality of performance of heat engines with internal and external irreversibilities. Chen 
et al. [13] concur with these findings from the considerations of finite time thermodynamics. This is further remphasized in the work of Roco et al. [14] for the case of air based regenerative Brayton cycles. Important conclusion of these papers is the fact that the desired performance indicators, namely the efficiency and power output do not share a common maximum point. Analogously, even in the case of heat pumps, the coefficient of performance (COP) and cooling/heating capacity do not have a common optimum operating point [15-17]. General appreciation of how these performance indicators behave is realized by evaluating each of them against several system variables such as operating pressure and volume in the cycle, pressure ratio and/or temperature of heat source and sink. Such an approach often results in the use of multiple plots for extracting information about optimum operating point. On the other hand, the two path function coordinate system comprising of thermal efficiency/COP and power output/cooling or heating capacity appears to provide a deeper insight on the exact nature of performance of a heat engine or a heat pump.

The objective of this paper is to further explore the above two path function coordinate system to understand the intricate link between the performance indicators and cycle operating parameters for the specific case of $\mathrm{CO}_{2}$ Brayton cycle power plants. This study is motivated by recent developments in concentrated solar power using $\mathrm{CO}_{2}$ based Brayton cycles [1,2,18-25]. Recently, Mohagheghi et al. [26] used Pareto-based multi objective optimization for optimizing the process parameters of transcritical regenerative $\mathrm{CO}_{2}$ Brayton cycle. Results thereof were presented using the above co-ordinate system for expansion ratios ranging from 3.2 to 16 . However, earlier findings $[1,19]$ indicate that the optimal expansion ratios in trans- and supercritical cycles seldom exceed 4. 
In this paper, the possible domain of operation is found to lie between the point of maximum efficiency and maximum work output. But, some limitations exist in the region of maximum work output from operating pressures point of view and hence, an attempt is made to elucidate how compromises need to be made to generate a control strategy for effective power management. This is akin to the situation in transcritical $\mathrm{CO}_{2}$ refrigeration cycle where maximization of cooling capacity requires high compressor discharge pressures [27]. Detailed analysis carried out in this paper highlights the possible operating domains on the efficiency versus net specific work output plot for fixed heat source temperature (as in the case of conventional power generation) and when it is transient (as in the case of CSP).

\section{Mathematical approach}

Fig. 1 shows the schematic of a standard Brayton cycle with regeneration. The heat transfer fluid entering the boiler derives heat either from a nuclear reactor coolant or from the thermal storage unit of CSP system. For given source and sink temperatures, performance indicators like efficiency and specific work output are significantly influenced by the expansion ratio [1]. In order to arrive at an optimum operating condition for a power cycle, one needs to understand the mutual dependence among these three parameters which is given below.

$$
\begin{aligned}
& \eta_{\text {th,no-regeneration }}=\frac{\left(h_{3}-h_{4}\right)-\left(h_{2}-h_{1}\right)}{h_{3}-h_{2}} \\
& \eta_{\text {th,regeneration }}=\frac{\left(h_{3}-h_{4}\right)-\left(h_{2}-h_{1}\right)}{h_{3}-h_{5}} \\
& w_{s p}=\left(h_{3}-h_{4}\right)-\left(h_{2}-h_{1}\right)
\end{aligned}
$$

To analyze the effect of expansion ratio $\left(r=p_{3} / p_{4}\right), p_{1}, T_{1}$ and $T_{3}$ are fixed. 
a) Condition for maximum thermal efficiency without regeneration

For the case of no regeneration, maximum thermal efficiency requires that

$d \eta_{\text {th,no-regeneration }} / d p_{3}=0$

$\frac{\partial \eta_{\text {th,no-regeneration }}}{\partial p_{3}}=\left[\left(h_{3}-h_{2}\right)\left(\left.\frac{\partial h_{3}}{\partial p_{3}}\right|_{T_{3}}-\left.\frac{\partial h_{4}}{\partial p_{3}}\right|_{s_{4}}-\left.\frac{\partial h_{2}}{\partial p_{3}}\right|_{s_{1}}\right)-\left(\left(h_{3}-h_{4}\right)-\left(h_{2}-h_{1}\right)\right)\left(\left.\frac{\partial h_{3}}{\partial p_{3}}\right|_{T_{3}}-\left.\frac{\partial h_{2}}{\partial p_{3}}\right|_{s_{1}}\right)\right]$

which is rewritten in the following form

$\frac{\partial \eta_{\text {th,no-regeneration }}}{\partial p_{3}}=\left[\left(h_{3}-h_{2}\right)\left(-\left.\frac{\partial h_{4}}{\partial p_{3}}\right|_{s_{4}}\right)-\left(h_{4}-h_{1}\right)\left(\left.\frac{\partial h_{3}}{\partial p_{3}}\right|_{T_{3}}-\left.\frac{\partial h_{2}}{\partial p_{3}}\right|_{s_{1}}\right)\right]=0$

\section{b) Condition for maximum thermal efficiency with regeneration}

If turbine exhaust heat is gainfully deployed for augmenting the enthalpy of compressor discharge stream through regeneration, eq. (6) becomes

$$
\frac{\partial \eta_{\text {th, regeneration }}}{\partial p_{3}}=\left[\left(h_{3}-h_{5}\right)\left(\left.\frac{\partial h_{3}}{\partial p_{3}}\right|_{T_{3}}-\left.\frac{\partial h_{4}}{\partial p_{3}}\right|_{S_{4}}-\left.\frac{\partial h_{2}}{\partial p_{3}}\right|_{S_{1}}\right)-\left[\left(h_{3}-h_{4}\right)-\left(h_{2}-h_{1}\right)\right]\left(\left.\frac{\partial h_{3}}{\partial p_{3}}\right|_{T_{3}}-\left.\frac{\partial h_{5}}{\partial p_{3}}\right|_{T_{5}}\right)\right]
$$

Applying $1^{\text {st }}$ law of thermodynamics to regenerator

$h_{5}=h_{2}+h_{4}-h_{6}$

from which $\left.\frac{\partial h_{5}}{\partial p_{3}}\right|_{T_{5}}=\left.\frac{\partial h_{2}}{\partial p_{3}}\right|_{s_{2}}+\left.\frac{\partial h_{4}}{\partial p_{3}}\right|_{s_{4}}-\left.\frac{\partial h_{6}}{\partial p_{3}}\right|_{T_{6}}$ 
Eq. (7) takes the following form

$$
\frac{\partial \eta_{\text {th, regeneration }}}{\partial p_{3}}=\left[\begin{array}{l}
\left(h_{3}-h_{5}\right)\left(\left.\frac{\partial h_{3}}{\partial p_{3}}\right|_{T_{3}}-\left.\frac{\partial h_{4}}{\partial p_{3}}\right|_{s_{4}}-\left.\frac{\partial h_{2}}{\partial p_{3}}\right|_{s_{1}}\right)- \\
{\left[\left(h_{3}-h_{4}\right)-\left(h_{2}-h_{1}\right)\right]\left\{\left.\frac{\partial h_{3}}{\partial p_{3}}\right|_{T_{3}}-\left(\left.\frac{\partial h_{2}}{\partial p_{3}}\right|_{s_{2}}+\left.\frac{\partial h_{4}}{\partial p_{3}}\right|_{s_{4}}-\left.\frac{\partial h_{6}}{\partial p_{3}}\right|_{T_{6}}\right)\right.}
\end{array}\right]=0
$$

c) Condition for maximum $w_{s p}$

Maximization of $w_{s p}$ requires that

$d w_{s p} / d p_{3}=0$

Differentiating eq. (3) w.r.t. $p_{3}$

$$
\frac{\partial w_{s p}}{\partial p_{3}}=\left.\frac{\partial h_{3}}{\partial p_{3}}\right|_{T_{3}}-\left.\frac{\partial h_{4}}{\partial p_{3}}\right|_{s_{4}}-\left.\frac{\partial h_{2}}{\partial p_{3}}\right|_{s_{1}}=0
$$

It is unlikely that solutions to eqs. (6), (10) and (12) will yield identical expansion ratio. Since no closed form solutions are possible, optimum expansion ratios are evaluated numerically.

To illustrate the benefit of efficiency-specific work output coordinate system, in the first instance, above equations are simplified using ideal gas laws. Appendix A provides detailed mathematical modeling of the ideal Brayton cycle. Fig. 2 shows air standard Brayton cycle with and without regeneration on this coordinate system for fixed operating conditions $\left(p_{1}, T_{1}\right.$ and $\left.T_{3}\right)$. The following observations are pertinent:

i. maximum specific work output (B) is independent of amount of heat recovered in the regenerator. 
ii. for cycles with regeneration, the direction of increase in expansion ratio is clock-wise from A to $\mathrm{B}$, whereas, for cycles without regeneration, it is counter clockwise from $\mathrm{C}$ to $\mathrm{A}$.

iii. to achieve the same efficiency, regenerative power cycles require lower expansion ratios as compared to cycles without regeneration.

At $\mathrm{B}, T_{4}=T_{2}$; and thereafter (between $\mathrm{B}$ and $\mathrm{C}$ ) no more regeneration is possible. Therefore, for cycles with regeneration, expansion ratio at B is the maximum operating limit. However, there is no such restriction for cycles without regeneration which can be operated beyond B up to A.

In the following sections, real gas effects are incorporated in the analysis as they cannot be ignored in the zone of operation of $\mathrm{CO}_{2}$ Brayton cycles.

\section{Performance evaluation of $\mathrm{CO}_{2}$ Brayton cycles}

Having established apriori additional benefits of the thermal efficiency and specific work coordinate system for an ideal Brayton cycle, it will now be extended to $\mathrm{CO}_{2}$ Brayton cycles, wherein, irreversibilities in turbo-machinery and heat exchangers are accounted for. The two possible thermodynamic cycles considered in further sections, namely, transcritical noncondensing $\left(\mathrm{TN}-\mathrm{CO}_{2}\right)$ and supercritical $\left(\mathrm{S}-\mathrm{CO}_{2}\right)$ are shown in Fig. 3. The interest in $\mathrm{CO}_{2}$ based cycles arises as a part of our effort to explore them for possible power generation using CSP $[1,19]$. There have been some studies suggesting the use of supercritical $\mathrm{CO}_{2}$ for nuclear power generation also [19-25].

\subsection{Assumptions}


The methodology adopted in accommodating non-idealities in compression, expansion, heat transfer and fluid flow has been explained in $[1,28,29]$. However, for the sake of completeness, the assumptions are briefly enumerated below.

i. isentropic efficiencies of the turbine and compressor:

$$
\begin{gathered}
\eta_{t}=\frac{\left(h_{3^{\prime}}-h_{4^{\prime}}\right)}{\left(h_{3^{\prime}}-h_{4}\right)}=0.75 \\
\eta_{\text {comp }}=\frac{\left(h_{2}-h_{1}\right)}{\left(h_{2^{\prime}}-h_{1}\right)}=0.80
\end{gathered}
$$

ii. a minimum temperature difference of $10 \mathrm{~K}$ is required between warm and cold streams in heat addition process and in the regenerator. For example, $T_{6}-T_{2^{\prime}} \geq 10 \mathrm{~K}$.

iii. a pressure drop of $3.5 \%$ of entry pressure occurs in each stream during the heat addition and heat rejection processes, i.e. $p_{3}=0.965 p_{2^{\prime}}, p_{1}=0.965 p_{4^{\prime}}$.

iv. characteristics of turbine and compressor do not vary as operating conditions change.

With the above non-idealities taken into account, eqs. (1-3) get modified as follows:

$$
\begin{aligned}
& \eta_{\text {th,no-regeneration }}=\frac{\left(h_{3^{\prime}}-h_{4^{\prime}}\right)-\left(h_{2^{\prime}}-h_{1}\right)}{h_{3^{\prime}}-h_{2}} \\
& \eta_{t h, \text { regeneration }}=\frac{\left(h_{3^{\prime}}-h_{4^{\prime}}\right)-\left(h_{2^{\prime}}-h_{1}\right)}{h_{3^{\prime}}-h_{5}} \\
& w_{s p}=\left(h_{3^{\prime}}-h_{4^{\prime}}\right)-\left(h_{2^{\prime}}-h_{1}\right)
\end{aligned}
$$

REFPROP 9.0 [30] is used to obtain real gas properties of $\mathrm{CO}_{2}$ in the range of interest of cycle pressures and temperatures. The lowest cycle temperature $\left(T_{1}\right)$ is set at $308 \mathrm{~K}$. Operational variables investigated are the highest cycle temperature $\left(T_{3^{\prime}}\right)$ which is varied between $500-1000$ $\mathrm{K}$, expansion ratios $\left(p_{3}, / p_{4}\right)$ and lowest cycle pressure $\left(p_{1}\right)$. 
A key feature of this paper is superposition of isotherms and isobars on the efficiencyspecific work output coordinate system to bring out their relevance in arriving at an algorithm for load management and control strategy.

\section{Results and discussions}

\section{1. $\mathrm{CO}_{2}$ Brayton Cycles}

Analysis of $\mathrm{TN}$ and $\mathrm{S}-\mathrm{CO}_{2}$ cycles is carried out for the two cases namely, a) with regeneration and b) without regeneration. In the case of $\mathrm{TN}-\mathrm{CO}_{2}$, the low side pressure is fixed at 50 bar, whereas for $\mathrm{S}_{-} \mathrm{CO}_{2}$ it is 75 bar. Fig. 4 presents a plot of $\eta_{t h} v s w_{s p}$ for a turbine inlet temperature $\left(T_{3^{\prime}}\right)$ of $1000 \mathrm{~K}$. The nature of upper cycle pressure dependence of derivatives [eqs (6), (10) and (12)] is given in the supplementary material. This isotherm is obtained by varying the expansion ratio. Considering real gas effects and irreversibilities in a power cycle, the direction of increase in expansion ratio is clockwise with regeneration and anti-clockwise without it as seen also in the ideas gas case in Fig. 2. Since cycles without regeneration offer efficiencies less than $\sim 50 \%$ of cycles with regeneration, former cycles are not of further interest. Hence, subscript regeneration is omitted in the subsequent discussions.

The isotherm in Fig. 4 can be divided into five distinct regions as below.
i. $\left.\left(\frac{\partial \eta_{t h}}{\partial w_{s p}}\right)_{T_{3}, T_{1}, p_{1}}\right|_{p_{2}<p_{2, B}}>0 \quad$ (region A-B)
ii. $\left.\left(\frac{\partial \eta_{t h}}{\partial w_{s p}}\right)_{T_{3}, T_{1}, p_{1}}\right|_{p_{2}=p_{2, B}}=0$ 
iii. $\left.\left(\frac{\partial \eta_{t h}}{\partial w_{s p}}\right)_{T_{3}, T_{1}, p_{1}}\right|_{p_{2} \in\left(p_{2, B}, p_{2, C}\right)}<0 \quad$ (region B-C)
iv. $\left.\left(\frac{\partial w_{s p}}{\partial \eta_{t h}}\right)_{T_{3}, T_{1}, p_{1}}\right|_{p_{2}=p_{2, C}}=0 \quad$ (C)
v. $\left.\left(\frac{\partial \eta_{t h}}{\partial w_{s p}}\right)_{T_{3}, T_{1}, p_{1}}\right|_{p_{2}>p_{2, C}}>0$
(right wing of isotherm below zone C)

Referring to Fig. 4, B denotes the point of maximum thermal efficiency (region ii). Descending from $\mathrm{B}$ in the direction of increasing expansion ratio, the point of maximum specific work at $\mathrm{C}$ is reached. After this point, both efficiency and specific work output decrease with further increase in expansion ratio (region $v$ ) and hence, this region is not expected to be of interest. Qualitatively, isotherms for both cycles are alike (Fig. 4), but quantitatively, $\eta_{t h, \max }$ and $w_{s p \text {, max }}$ are higher for the $\mathrm{S}-\mathrm{CO}_{2}$ cycle than $\mathrm{TN}-\mathrm{CO}_{2}$ cycle. Further, the dome $\mathrm{ABC}$ is substantially different, the implications of which are discussed hereunder.

In any power cycle, maximum benefits are more likely to be derived when the operating domain falls in the region between B and C. Selection of operating point of a power plant depends on the type of heat source available (solar, geothermal, nuclear, fossil fuel etc.). In the case of non-solar power plants (nuclear or coal based) the cost of the infrastructure far exceeds the cost of energy source. The system designer will select operation in the region closer to $\mathrm{C}$ such that the power delivered to the grid is maximized resulting in enhanced revenues. However, this criterion may not be applicable for a solar thermal plant where the cost of concentrated solar 
field and the associated thermal storage system are significantly higher than the cost of plant itself.

\subsubsection{Load Modulation in Non-Solar Thermal Power Plants}

In an ideal power plant demand and supply should be well matched necessitating load modulation. Presently, methods like throttle governing and nozzle governing [31-33] are used in steam based plants. In the case of throttle governing, turbine expansion ratios are varied by throttling the working fluid after heat addition, whereas, in the case of nozzle governing, enthalpy drop in the turbine is regulated using a set of nozzles [31-33].

In Rankine cycle based power plants, the ratio of pump work to turbine work is insignificant $(<0.10 \%)$ compared to Brayton cycles, where compressor consumes nearly $1 / 3$ of the power generated by the turbine [1]. Hence, conventional methods used for load regulation (throttle and nozzle governing) in Rankine plants would be inappropriate for modulating the load in Brayton cycle plants. There are numerous techniques for modulating the output of an open loop Brayton cycle, the most common being regulating the air/fuel ratio of the mixture to control the rate of heat addition [34-36] which is inapplicable for a closed loop $\mathrm{CO}_{2}$ Brayton cycle.

For a given mass flow rate, the output of a power plant operating in a closed loop can be modulated by varying the specific work output. With no further sacrifice in the efficiency below point $\mathrm{C}$, the possible domain of load regulation is from $w_{s p, A}$ and $w_{s p, C}$ corresponding to points A and $\mathrm{C}$, each of which have a unique expansion ratio associated with them.

Increasing expansion ratio from $\mathrm{A}$ to $\mathrm{C}$ has a positive impact on thermal efficiency, which peaks at $\mathrm{B}$. In $\mathrm{CO}_{2}$ cycles, it may be impractical to operate at $\mathrm{C}$, where high side pressures $\left(p_{2}\right)$ can be $>300$ bar for certain isotherms, which is explained in the next section. Hence, the maximum cycle pressure is limited to 300 bar for further discussion. In such cases, it is no longer 
possible to operate at the point of maximum specific work output (C). The location of maximum possible work corresponding to $p_{3^{\prime}}{ }^{\prime}=300$ bar (such as C') moves towards B. Its consequences are discussed in detail in a following section. Referring to Fig. 4, part load performance indicators are defined as follows:

i. $(\Delta w)_{A-C}\left[\right.$ or $\left.(\Delta w)_{A-C}\right]=$ range of specific work regulation

ii. $(\Delta \eta)_{B-D}=$ net sacrifice in thermal efficiency due to load regulation $(\Delta w)_{A-C}\left[\right.$ or $\left.(\Delta w)_{A-C^{\prime}}\right]$

Ideally, it is desirable to design a power plant with a large range in $(\Delta w)_{A-C}$ [or $\left.(\Delta w)_{A-C^{\prime}}\right]$ with minimal sacrifice in $(\Delta \eta)_{B-D}$. Fig. 5 illustrates the variation in $(\Delta w)_{A-C}\left[\right.$ or $\left.(\Delta w)_{A-C^{\prime}}\right]$ and $(\Delta \eta)_{B-D}$ along different isotherms for TN- and S- $\mathrm{CO}_{2}$ cycles. Both, $(\Delta w)_{A-C}$ [or $\left.(\Delta w)_{A-C^{\prime}}\right]$ and $(\Delta \eta)_{B-D}$ increase with increase in source temperature for each of the cycles. $\mathrm{TN}-\mathrm{CO}_{2}$ cycle offers a wider range of load regulation for turbine inlet temperatures higher than $\sim 820 \mathrm{~K}$ with a marginal sacrifice in thermal efficiency.

In a power plant, the change in load is traditionally represented as a fraction of full load corresponding to point $\mathrm{C}$ (or C'). Fig. 6 shows normalized load regulation, $(\Delta w)_{A-} d w_{C}$ [or $(\Delta w)_{A-}$ $\left.C^{\circ} / w_{C}\right]$ vs normalized efficiency sacrifice, $(\Delta \eta)_{B-D} / \eta_{B}$. In the case of $\mathrm{TN}^{-} \mathrm{CO}_{2}$ cycle, the percentage load regulation is as high as $75 \%$ at the expense of $18 \%$ change in fractional efficiency at $1000 \mathrm{~K}$. On the other hand, for a $\mathrm{S}-\mathrm{CO}_{2}$ cycle, $(\Delta w)_{A-C} / w_{C}\left[\right.$ or $\left.(\Delta w)_{A-C} / w_{C^{\prime}}\right]$ is relatively immune to source temperature variation, whether it be fractional change of load or efficiency.

\subsubsection{Modulation of Concentrated Solar Power Plants}

A solar thermal power plant is designed to convert the available heat to work with maximum efficiency so as to make effective use of solar field associated with it. Unlike fossil fuel based or nuclear plants which are characterized by steady turbine inlet temperatures, the 
source temperature in a solar based unit depends on a number of factors such as cloud cover, time of the day, resulting in large fluctuations. Consequently, the emphasis of load regulation shifts from demand based manipulation to adjustments imposed by source temperature variations.

The effect of variation in source temperature is brought out through a number of isotherms shown in Figs. 7 and 8 for $\mathrm{TN}$ - and $\mathrm{S}-\mathrm{CO}_{2}$ cycles respectively. The nature of isotherms is such that for a given efficiency there can be two specific work output values and two high side pressures. Similarly for a given specific work output there can be two efficiencies and corresponding high side pressures. Isobars corresponding to high side pressures are superposed in these figures from 100 to 300 bar in the steps of 50 bar. Unlike isotherms, intersection of an isobar with an iso-efficiency line results in a unique isotherm and a unique specific work output. This is true in case of intersection of isobar and iso-specific work output line also. Thus, isobars can be said to be explicit given any two of the other three parameters, temperature, efficiency and specific work output. Loci of the maxima of efficiency (point B in Fig. 4) and specific work output (point $\mathrm{C}$ in Fig. 4) are also shown therein. It is apparent that the point of intersection of the 300 bar isobar (C') and some of the high temperature isotherms can be between B and C. This occurs for isotherms greater than about $\sim 930 \mathrm{~K}$ for $\mathrm{TN}-\mathrm{CO}_{2}$ and $\sim 700 \mathrm{~K}$ for $\mathrm{S}-\mathrm{CO}_{2}$ cycles.

In a solar power plant where varying source temperatures are inevitable, one would prefer the operational strategy to follow the locus of maximum thermal efficiency (point B). Table 1 lists the data of optimum expansion ratio and maximum efficiency along each isotherm i.e. the locus of point B. From Figs. 7 and 8 and Table 1, it can be deduced that operation with a source temperature of $<700 \mathrm{~K}$ yields deplorable efficiencies for both the cycles. Also, Fig. 6 confirms that, a steady ramp for all parameters exists only above $700 \mathrm{~K}$. In view of this, the empirical 
relations are developed for temperature range of 700 and $1000 \mathrm{~K}$ and are given below where the temperature is in $\mathrm{K}$.

For optimum expansion ratio

$$
\begin{array}{ll}
r_{\text {optimum }, \text { efficiency }}=1.33 \times 10^{-3} \mathrm{~T}+1.03 & \left(\text { for } \mathrm{TN}-\mathrm{CO}_{2}\right. \text { cycle) } \\
r_{\text {optimum }, \text { efficiency }}=2.52 \times 10^{-3} \mathrm{~T}+0.72 & \left(\text { for } \mathrm{S}-\mathrm{CO}_{2} \text { cycle }\right)
\end{array}
$$

Similar equations for optimum efficiencies

$$
\begin{aligned}
& \eta_{\text {optimum }}=5.6 \times 10^{-4} \mathrm{~T}-0.23 \quad \text { (for } \mathrm{TN}-\mathrm{CO}_{2} \text { cycle) } \\
& \eta_{\text {optimum }}=4.6 \times 10^{-4} T-0.12 \quad \text { (for } \mathrm{S}^{-\mathrm{CO}_{2}} \text { cycle) }
\end{aligned}
$$

It is also observed from Figs. 7 and 8 that the locus of $\eta_{\text {optimum }}$ can be correlated by the equations given below from which the specific power attainable (in $\mathrm{kJ} / \mathrm{kg}$ ) can be calculated.

$$
\begin{aligned}
& \eta_{\text {optimum }}=4.44 \times 10^{-3} w_{s p}+8.13 \times 10^{-2} \quad \text { (for } \mathrm{TN}^{-} \mathrm{CO}_{2} \text { cycle) } \\
& \left.\eta_{\text {optimum }}=2.57 \times 10^{-3} w_{s p}+1.09 \times 10^{-2} \quad \text { (for } \mathrm{S}^{-} \mathrm{CO}_{2} \text { cycle }\right)
\end{aligned}
$$

The variation of efficiency and specific power along each isobar is also correlated and the resulting equations are given below where $p_{2}$, (in bar) and $w_{s p}$ (in $\mathrm{kJ} / \mathrm{kg}$ ).

$$
\begin{aligned}
\eta_{\text {optimum }}= & \left(1.09 \times 10^{-7} p_{2^{\prime}}^{2}-5.75 \times 10^{-5} p_{2^{\prime}}+1.06 \times 10^{-2}\right) w_{s p}+ \\
& \left(-3.54 \times 10^{-7} p_{2^{\prime}}^{2}-2.05 \times 10^{-5} p_{2^{\prime}}+6.25 \times 10^{-2}\right)
\end{aligned}
$$

(for $\mathrm{TN}-\mathrm{CO}_{2}$ cycle)

$$
\begin{gathered}
\eta_{\text {optimum }}=\left(8.11 \times 10^{-8} p_{2^{\prime}}^{2}-4.71 \times 10^{-5} p_{2^{\prime}}+9.62 \times 10^{-3}\right) w_{s p}+ \\
\left(6.72 \times 10^{-10} p_{2^{\prime}}^{3}-2.23 \times 10^{-6} p_{2^{\prime}}^{2}+9.03 \times 10^{-4} p_{2^{\prime}}-2.09 \times 10^{-2}\right) \\
\left(\text { for } \mathrm{S}^{-} \mathrm{CO}_{2} \text { cycle }\right)
\end{gathered}
$$


For example, an $\mathrm{S}-\mathrm{CO}_{2}$ cycle operating at $1000 \mathrm{~K}$ has optimum high side pressure of 258 bar $\left(r_{\text {optimum,efficiency }}=3.22\right)$. If the solar conditions deteriorate to a state compelling operation at $850 \mathrm{~K}$, the optimum expansion ratio and obtainable maximum efficiency can be calculated using eqs. (19) and (21) as 2.86 (230 bar) and $27.1 \%$, respectively. Using eq. (23), the specific work at this operating condition is estimated to be $64 \mathrm{~kJ} / \mathrm{kg}$. If the specific work is greater than this value (as measured in the plant), then the operating high side pressure has to be reduced to move the operating point back to the maximum efficiency point (point B) or vice versa. Examination of Fig. 8 also shows that the spread in high side pressure at maximum efficiency between 700 to $1000 \mathrm{~K}$ is between 198 and 258 bar, which is quite narrow. Further, the plateau like behavior of isotherms in this region also suggests that even if exact high side pressure control is not done, the loss in efficiency is marginal.

In summary, we have developed a number of empirical correlations relating the upper cycle pressure, heat source temperature, maximum efficiency and specific power. Together they can provide useful insights for developing control algorithms for solar based $\mathrm{CO}_{2}$ power plants. The challenge, however, lies in developing appropriate turbo-machinery which can handle varying expansion ratios.

In all the above sections, the lowest cycle temperature was fixed at $35^{\circ} \mathrm{C}$. If this changes, the isotherms will be different quantitatively with efficiencies and maximum specific workout decreasing with increasing ambient temperatures. The supplementary material provides typical changes that occur in Fig 4. Relative changes in performance indicators are also listed in tables therein.

\section{Conclusion}


This paper provides an operational strategy for regulating trans- and super-critical $\mathrm{CO}_{2}$ cycles using thermal efficiency-specific work output co-ordinate system. The efficacy of this coordinate system has been established for the cases of constant and variable source temperatures, the latter being inevitable in concentrated solar power systems. The following conclusions are derived from this study:

i. the above co-ordinate system permits determination of the direction of increasing expansion ratios which is in the clockwise direction with regeneration and counter clockwise without regeneration for a given source temperature isotherm.

ii. maximum specific work output is independent of regeneration effect.

iii. for closed loop Brayton cycles, turbine expansion ratio variation provides a viable means of load regulation.

iv. for conventional heat source power plants with source temperatures typically at $1000 \mathrm{~K}$ and operating at maximum specific power output point, $\mathrm{TN}-\mathrm{CO}_{2}$ and $\mathrm{S}-\mathrm{CO}_{2}$ cycles offer $\sim 80 \%$ and $\sim 50 \%$ load regulation with a sacrifice in thermal efficiency of $\sim 18 \%$ and $\sim 10 \%$ respectively. This suggests that a $\mathrm{TN}-\mathrm{CO}_{2}$ cycle offers better regulation possibilities compared to an $\mathrm{S}-\mathrm{CO}_{2}$ cycle.

v. for solar based power plants one would prefer operation at maximum efficiency irrespective of fluctuating heat source temperatures in view of large energy collection costs. The locus of maximum efficiency points for various source temperatures is nearly linear for both $\mathrm{TN}-\mathrm{CO}_{2}$ and $\mathrm{S}-\mathrm{CO}_{2}$ cycles in the region of interest. 
vi. a number of empirical correlations valid for 700-100 K source temperatures and 150-250 bar high side pressures have been derived to enable generation of a control algorithm for operation at maximum efficiency. However, in view of the plateau around the maximum efficiency point, high sophistication in control may not be needed.

\section{Acknowledgments}

This research is based upon work supported by the Solar Energy Research Institute for India and the U.S. (SERIIUS) funded jointly by the U.S. Department of Energy subcontract DE AC36-08G028308 (Office of Science, Office of Basic Energy Sciences, and Energy Efficiency

and Renewable Energy, Solar Energy Technology Program, with support from the Office of International Affairs) and the Government of India subcontract IUSSTF/JCERDCSERIIUS/2012 dated 22nd Nov. 2012. The authors are also grateful to Prof. Pradip Dutta for numerous stimulating discussions during the course of this research. 


\section{Appendix A}

\section{Mathematical modeling of the ideal Brayton cycle}

For an air standard Brayton cycle, using ideal gas assumptions, eqs. (1) to (3) can be simplified as below:

$$
w_{s p}=c_{p}\left[\left(T_{3}-T_{4}\right)-\left(T_{2}-T_{1}\right)\right]
$$

From isentropic relations,

$$
\begin{aligned}
& \frac{T_{2}}{T_{1}}=\left(\frac{p_{2}}{p_{1}}\right)^{\left(\frac{\gamma-1}{\gamma}\right)}=r^{\left(\frac{\gamma-1}{\gamma}\right)} \\
& \frac{T_{3}}{T_{4}}=\left(\frac{p_{3}}{p_{4}}\right)^{\left(\frac{\gamma-1}{\gamma}\right)}=r^{\left(\frac{\gamma-1}{\gamma}\right)}
\end{aligned}
$$

Eq. (A.2) can be expressed in terms of known quantities like $T_{1}, T_{3}, c_{p}$ and an independent variable $r$,

$$
w_{s p}=c_{p}\left(r^{\left(\frac{\gamma-1}{\gamma}\right)}-1\right)\left(\frac{T_{3}}{r^{\left(\frac{\gamma-1}{\gamma}\right)}-T_{1}}\right)
$$

Differentiating it with respect to $r$

$$
r_{\text {max }, w_{s p}}=\left(\frac{T_{3}}{T_{1}}\right)^{\frac{2 \gamma}{\gamma-1}}
$$

For the above expansion ratio, eqs. (A.2) and (A.3) yield $T_{2}=T_{4}$ when no further regeneration is possible. This is also the case because $w_{s p}$ is independent of regeneration. 
For the case without regeneration eq. (2) simplifies to

$\eta_{\text {th,no-regeneration }}=\frac{\left(T_{3}-T_{4}\right)-\left(T_{2}-T_{1}\right)}{T_{3}-T_{2}}$

Using isentropic relations

$$
\eta_{\text {th,no-regeneration }}=1-\frac{1}{r^{\left(\frac{\gamma-1}{r}\right)}}
$$

As per the above expression, thermal efficiency is independent of source and sink temperatures but monotonically increases with expansion ratio.

In the case of a power cycle with regeneration, eq. (3) becomes

$$
\eta_{\text {th,regeneration }}=\frac{\left(T_{3}-T_{4}\right)-\left(T_{2}-T_{1}\right)}{T_{3}-T_{5}}
$$

For $100 \%$ regeneration, implying zero approach temperature, $T_{6}=T_{2}$ and $T_{5}=T_{4}$

$\eta_{\text {th,regeneration }}=\frac{\left(T_{3}-T_{4}\right)-\left(T_{2}-T_{1}\right)}{T_{3}-T_{4}}$

Using isentropic relations

$$
\eta_{\text {th, regeneration }}=1-\frac{T_{1}}{T_{3}} r^{\left(\frac{\gamma-1}{\gamma}\right)}
$$

Efficiency again monotonically increases with expansion ratio for a given set of $T_{1}$ and $T_{3}$. 


\section{References}

[1] P. Garg, P. Kumar, K. Srinivasan, Supercritical carbon dioxide Brayton cycle for concentrated solar power, J. Supercritical Fluids 76 (2013) 54-60.

[2] B. D. Iverson, T. M. Conboy, J. J. Pasch, A. M. Kruizenga, Supercritical CO2 Brayton cycles for solar thermal energy, Applied Energy 111 (2013) 957-970.

[3] W. G. Le Roux, T. Bello-Ochende, J. P. Meyer, A review on the thermodynamic optimisation and modelling of the solar thermal Brayton cycle, Renewable \& Sustainable Energy Reviews 28 (2013) 677-690.

[4] Y. Haseli, Optimization of a regenerative Brayton cycle by maximization of a newly defined second law efficiency, Energy Conversion and Management 68 (2013) 133-140

[5] A. C. Hernandez, J. M. M. Roco, A. Medina, Power and efficiency in a regenerative gasturbine cycle with multiple reheating and intercooling stages, J. Physics D: Applied Physics 29 (1996) 1462-1468.

[6] C. Y. Cheng, C. K. Chen, Efficiency optimizations of an irreversible Brayton heat engine, J. Energy Resources Technology 120 (1998)143-148.

[7] C. Y. Cheng, C. K. Chen, Ecological optimization of an endo-reversible Brayton cycle, Energy Conversion and Management 39 (1998) 33-44.

[8] G. G. Aragon, P. A. Canales, G. A. Leon, M. M. Musharrafie, A criterion to maximize the irreversible efficiency in heat engines, J. Physics D: Applied Physics 36 (2003) 280-287.

[9] S. K. Tyagi, G. M. Chen, Q. Wang, S. C. Kaushik. Thermodynamic analysis and parametric study of an irreversible regenerative-intercooled-reheat Brayton cycle, International J. Thermal Sciences 45 (2006) 829-840. 
[10] F. L. Curzon, B. Ahlborn, Efficiency of a Carnot engine at maximum power output. American J. Physics, 43 (1975) 22-24.

[11] J. M. Gordon, M. Huleihil, On optimizing maximumpower heat engines, J. Applied Physics $69(1991) 1-7$.

[12] J. M. Gordon, M. Huleihil, General performance characteristics of real heat engines, J. Applied Physics 72 (1992) 829-837.

[13] J. Chen, Z. Yan, G. Lin, B. Andresen, On the Curzon-Ahlborn effciency and its connection with the effciencies of real heat engines, Energy Conversion and Management 42 (2001) $173-181$.

[14] J. M. M. Roco, S. Velasco, A. Medina, and A. Calvo Hernández, Optimum performance of a regenerative Brayton thermal cycle, J. Applied Physics 82 (1997), 2735-2741.

[15] J. M. Gordon, K. C. Ng, Thermodynamic modeling of reciprocating chillers, J. Applied Physics 75 (1993) 2769-2774.

[16] J. M. Gordon, K. C. Ng, H. T. Chua, Centrifugal chillers: thermodynamic modelling and a diagnostic case study, International J. Refrigeration 18 (1995) 253-257.

[17] J. M. Gordon, K. C. Ng, Cool Thermodynamics, Cambridge International Science, Cambridge, 2001.

[18] H. Yamaguchi, X. R. Zhang, K. Fujima, M. Enomoto, N. Sawada, Solar energy powered Rankine cycle using supercritical $\mathrm{CO}_{2}$, Applied Thermal Engineering 26 (2006) 2345-2354.

[19] V. Dostal, P. Hejzlar, M. J. Driscoll, N. E. Todreas, A supercritical $\mathrm{CO}_{2}$ Brayton cycle for advanced reactor applications, Transactions of American Nuclear Society 85 (2001) 110121. 
[20] T. Conboy, J. Pasch, D. Fleming, Control of a Supercritical CO2 Recompression Brayton Cycle Demonstration Loop, J. Engineering for Gas Turbines and Power, ASME, 135 (2013) $111701-111711$.

[21] S. Wright, T. Conboy, G. Rochau, Break-even transients for two simple recuperated Brayton test configurations, In: Supercritical CO2 power cycle symposium, Arvada, CO, May 24-25, 2011.

[22] T. Conboy, S. Wright, J. Pasch, G. Rochau, R. Fuller, Performance Characteristics of an Operating Supercritical CO2 Brayton Cycle, J. Engineering for Gas Turbines and Power, ASME, 134 (2012) 111703.

[23] T. Conboy, J. Pasch, Initial Split-Flow Operations of a Supercritical CO2 Recompression Brayton Cycle, Transactions of American Nuclear Society 106 (2012) 593-596.

[24] T. Conboy, Real gas effects in foil thrust bearings operating in the turbulent regime, J. Tribology, ASME, 135 (2013) 031703.

[25] S. A. Wright, R. F. Radel, M. E. Vernon, G. E. Rochau, P. S. Pickard, Operation and analysis of a supercritical CO2 Brayton Cycle, SAND2010-0171, (2010), Sandia National Laboratories, Albuquerque, NM.

[26] M. Mohagheghi, J. Kapat, N. Nagaiah, Pareto-Based Multi-Objective Optimization Of Recuperated S-CO2 Brayton Cycles, Proceedings of ASME Turbo Expo 2014: Turbine Technical Conference and Exposition, Düsseldorf, Germany, 2014, GT2014-27152.

[27] K. Srinivasan, P. Sheahen, C.S.P. Sarathy, Optimum thermodynamic conditions for upper pressure limits of transcritical carbon dioxide refrigeration cycle, International $\mathrm{J}$. Refrigeration 33 (2010) 1395-1401. 
[28] P. Garg, P. Kumar, K. Srinivasan, P. Dutta, Evaluation of isopentane, R-245fa and their mixtures as working fluids for organic Rankine cycles, Applied Thermal Engineering 51 (2013) 292-300.

[29] P. Garg, P. Kumar, K. Srinivasan, P. Dutta, Evaluation of carbon dioxide blends with isopentane and propane as working fluids for organic Rankine cycles, Applied Thermal Engineering 52 (2013) 439-448.

[30] E. W. Lemmon, M. L. Huber, M. O. McLinden. NIST Standard Reference Data Base 23: Reference Fluid Thermodynamic and Transport Properties-REFPROP. Version 9.0, National Institute of Standards and Technology, Standard Reference Data Program, Gaithersburg: 2010.

[31] W. B. Jachens, Steam turbines - their construction, selection and operation, Proc. South Africa Sugar Technical Association, 1966, 113-131.

[32] A. S. Leyzerovich, Steam turbines for modern fossil-fuel power plants, $1^{\text {st }}$ ed., The Fairmont Press Inc., Lilburn, 2008.

[33] H. P. Bloch, M. P. Singh, Steam turbines design: applications and rerating, $2^{\text {nd }}$ ed., New York, The McGraw-Hill, 2009.

[34] A. Andreini, B. Facchini, Gas turbines design and off-design performance analysis with emissions evaluation, J. Engineering for Gas Turbines and Power, ASME, 126 (2004) 8391.

[35] J. D. Mattingly, Elements of gas turbine propulsion, 1st ed., New York, The McGraw-Hill, 2005.

[36] J. H. Horlock, Advanced gas turbine cycles, Amsterdam, Elsevier Science Ltd., 2003. 


\section{List of Tables}

Table 1. Optimum cycle efficiency and its corresponding expansion ratio at different source temperatures for $\mathrm{TN}-\mathrm{CO}_{2}$ (for $p_{1}=50$ bar) and $\mathrm{S}-\mathrm{CO}_{2}$ (for $p_{1}=75$ bar) cycles 


\section{List of figures}

Fig. 1. Schematic of power plant

Fig. 2. Efficiency $v s$ net specific work for air Brayton cycle with $p_{1}=1$ bar, $T_{1}=308 \mathrm{~K}, T_{3}=$ 1000 K. Legend: $\square$ without regeneration, $\bigcirc$ with regeneration

Fig. 3. $\mathrm{CO}_{2}$ Brayton cycles on $p$ - $h$ chart. Legend: $-\cdot-\cdot-\mathrm{TN}-\mathrm{CO}_{2},-\mathrm{S}-\mathrm{CO}_{2}$

Fig. 4. Efficiency $v$ net specific work for $\mathrm{TN}-\mathrm{CO}_{2}$ and $\mathrm{S}-\mathrm{CO}_{2}$ cycle at $T_{3^{\prime}}=1000 \mathrm{~K}$. Legend: - with regeneration, --- without regeneration, $\square \mathrm{TN}-\mathrm{CO}_{2}$ cycle $\left(p_{1}=50\right.$ bar $), \circ \mathrm{S}-\mathrm{CO}_{2}$ cycle $\left(p_{1}=75\right.$ bar). Direction of increase in $p_{2^{\prime}}$ is clockwise for a cycle with regeneration and anti-clockwise when the cycle is without regeneration.

Fig. 5. $(\Delta w)_{A-C}$ or $(\Delta w)_{A-C}$, (possible change in load) and $(\Delta \eta)_{B-D}$ (corresponding change in efficiency) vs $T_{3^{\prime}}$ (source temperature). Legend: $-(\Delta w)_{A-C}$ or $(\Delta w)_{A-C}$ (left ordinate), --$(\Delta \eta)_{B-D}$ (right ordinate), $\square \mathrm{TN}-\mathrm{CO}_{2}$ cycle $\left(p_{I}=50\right.$ bar $), \circ \mathrm{S}-\mathrm{CO}_{2}$ cycle $\left(p_{I}=75\right.$ bar $)$

Fig. 6. $(\Delta w)_{A-C} / w_{C}$ or $(\Delta w)_{A-C}, w_{C}$ (possible fractional change in load) and $(\Delta \eta)_{B-D} / \eta_{B}$ (corresponding fractional change in efficiency) vs $T_{3^{\prime}}$ (source temperature). Legend: $-(\Delta w)_{A-}$ ${ }_{C} / w_{C}$ or $(\Delta w)_{A-C} / w_{C}$ (left ordinate), $---(\Delta \eta)_{B-D} / \eta_{B}$ (right ordinate), $\square \mathrm{TN}-\mathrm{CO}_{2}$ cycle $\left(p_{I}=50\right.$ bar), $\circ \mathrm{S}-\mathrm{CO}_{2}$ cycle $\left(p_{1}=75\right.$ bar $)$

Fig. 7. Efficiency vs net specific work for $\mathrm{TN}-\mathrm{CO}_{2}$ cycle. Legend: - isotherms, --- locus of $\eta_{\max }, \cdots \cdots \cdots$ locus of $W_{\max },-\cdot-\cdot-$ isobar $\left(p_{2^{\prime}}\right), \diamond p_{2^{\prime}}=100$ bar, $\square p_{2^{\prime}}=150$ bar, $\Delta p_{2^{\prime}}=200$ bar, $\circ p_{2^{\prime}}=250 \mathrm{bar}, \times p_{2^{\prime}}=300 \mathrm{bar}$ 
Fig. 8. Efficiency $v s$ net specific work for $\mathrm{S}-\mathrm{CO}_{2}$ cycle. Legend: — isotherms, - - - locus of $\eta_{\max }, \cdots \cdots \cdots$ locus of $w_{s p, \max },-\cdot-\cdot-$ isobar $\left(p_{2^{\prime}}\right), \diamond p_{2^{\prime}}=100$ bar, $\square p_{2^{\prime}}=150$ bar, $\Delta p_{2^{\prime}}=200$ bar, $\circ p_{2^{\prime}}=250$ bar, $\times p_{2^{\prime}}=300$ bar 
Table 1. Optimum cycle efficiency and its corresponding expansion ratio at different source temperatures for $\mathrm{TN}-\mathrm{CO}_{2}$ (for $p_{1}=50 \mathrm{bar}$ ) and $\mathrm{S}-\mathrm{CO}_{2}$ (for $p_{1}=75$ bar) cycles

\begin{tabular}{|c|c|c|c|c|}
\hline \multirow[b]{2}{*}{$T_{3},(\mathrm{~K})$} & \multicolumn{2}{|c|}{$r_{\text {optimum,efficiency }}$} & \multicolumn{2}{|c|}{$\eta_{\text {optimum }}(\%)$} \\
\hline & $\mathrm{TN}-\mathrm{CO}_{2}$ cycle & $\mathrm{S}-\mathrm{CO}_{2}$ cycle & $\mathrm{TN}-\mathrm{CO}_{2}$ cycle & $\mathrm{S}-\mathrm{CO}_{2}$ cycle \\
\hline 600 & 1.77 & 2.15 & 8.16 & 14.48 \\
\hline 700 & 1.95 & 2.47 & 15.86 & 20.61 \\
\hline 800 & 2.12 & 2.75 & 22.34 & 25.89 \\
\hline 900 & 2.25 & 3.02 & 27.84 & 30.50 \\
\hline 1000 & 2.35 & 3.22 & 32.58 & 34.54 \\
\hline
\end{tabular}




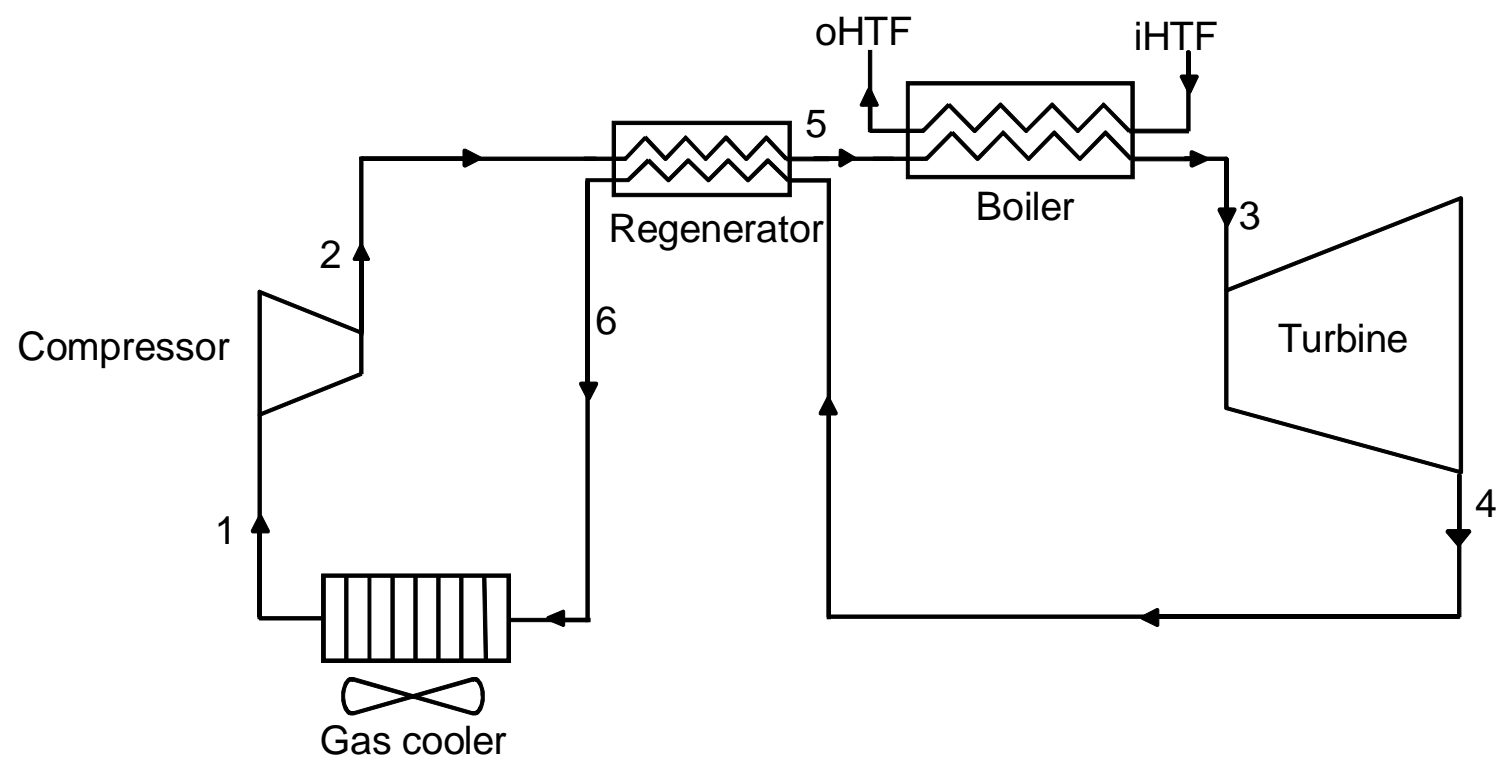

Fig. 1. Schematic of power plant 


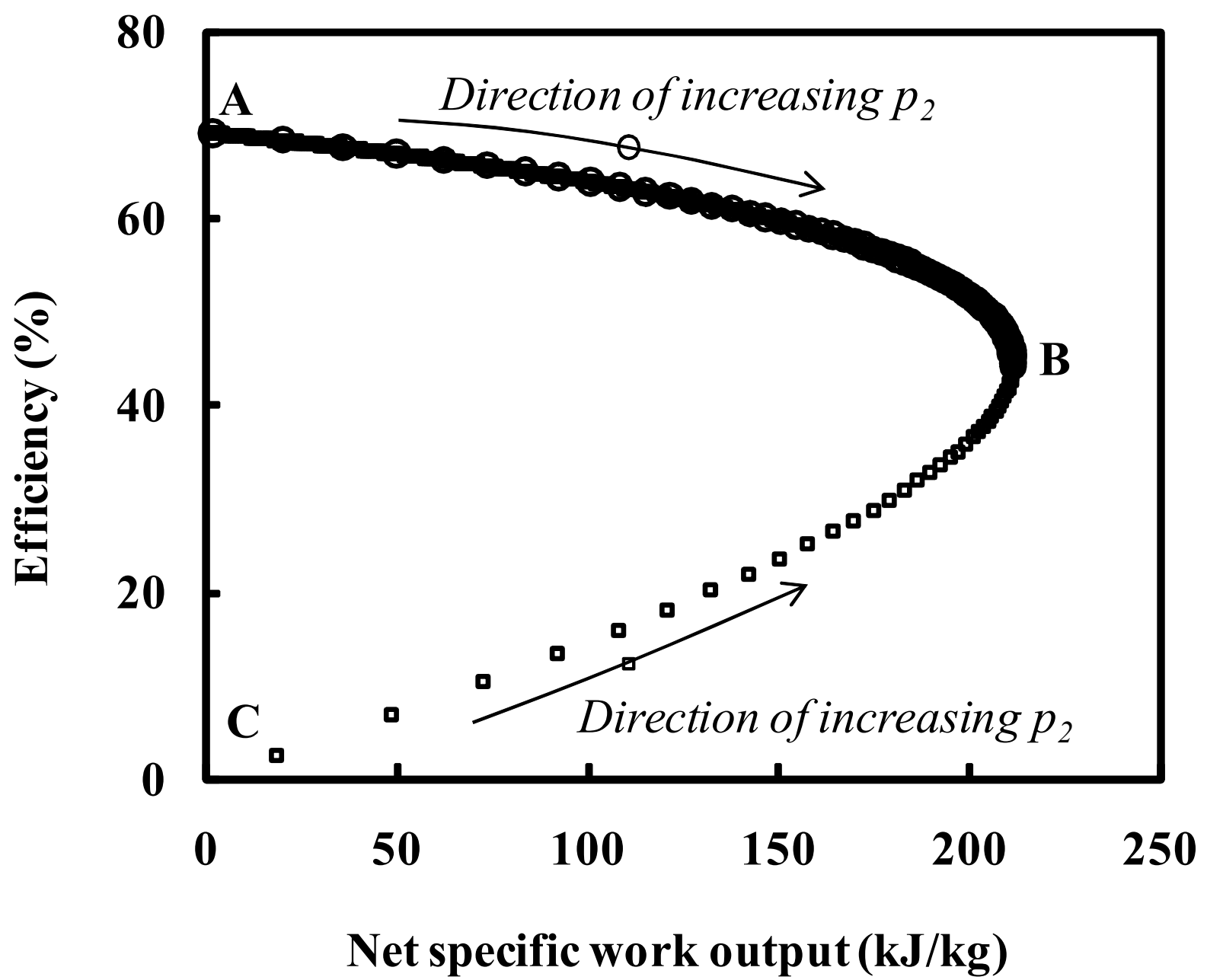

Fig. 2. Efficiency $v s$ net specific work for air Brayton cycle with $p_{1}=1$ bar, $T_{1}=308 \mathrm{~K}, T_{3}=$ 1000 K. Legend: $\square$ without regeneration, $\bigcirc$ with regeneration 


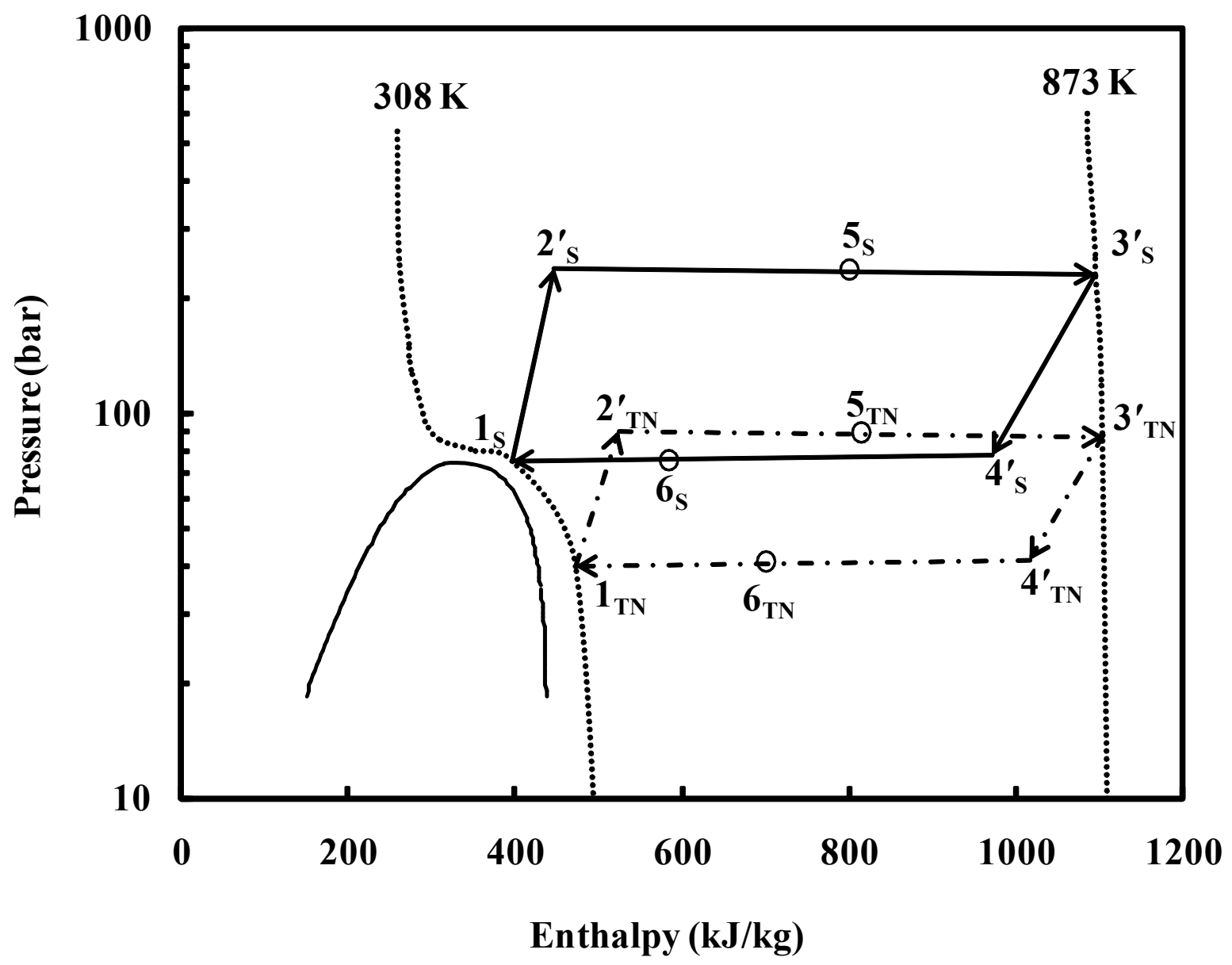

Fig. 3. $\mathrm{CO}_{2}$ Brayton cycles on $p-h$ chart. Legend: $-\cdot \cdot \cdot-\mathrm{TN}-\mathrm{CO}_{2},-\mathrm{S}-\mathrm{CO}_{2}$ 


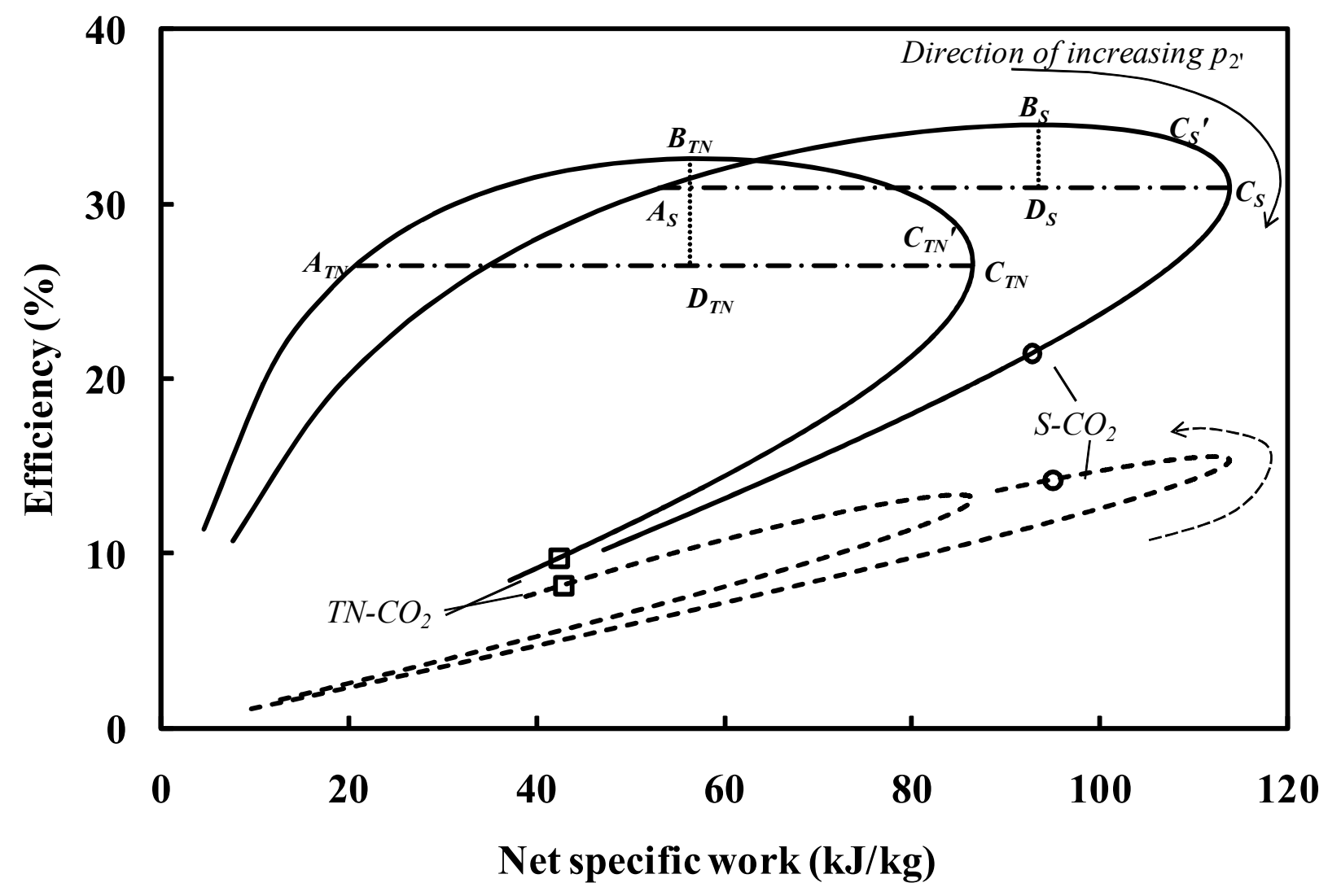

Fig. 4. Efficiency $v s$ net specific work for $\mathrm{TN}-\mathrm{CO}_{2}$ and $\mathrm{S}-\mathrm{CO}_{2}$ cycle at $T_{3^{\prime}}=1000 \mathrm{~K}$. Legend: — with regeneration, --- without regeneration, $\square \mathrm{TN}-\mathrm{CO}_{2}$ cycle $\left(p_{1}=50\right.$ bar $), \circ \mathrm{S}-\mathrm{CO}_{2}$ cycle ( $p_{1}=75$ bar). Direction of increase in $p_{2^{\prime}}$ is clockwise for a cycle with regeneration and anti-clockwise when the cycle is without regeneration. 


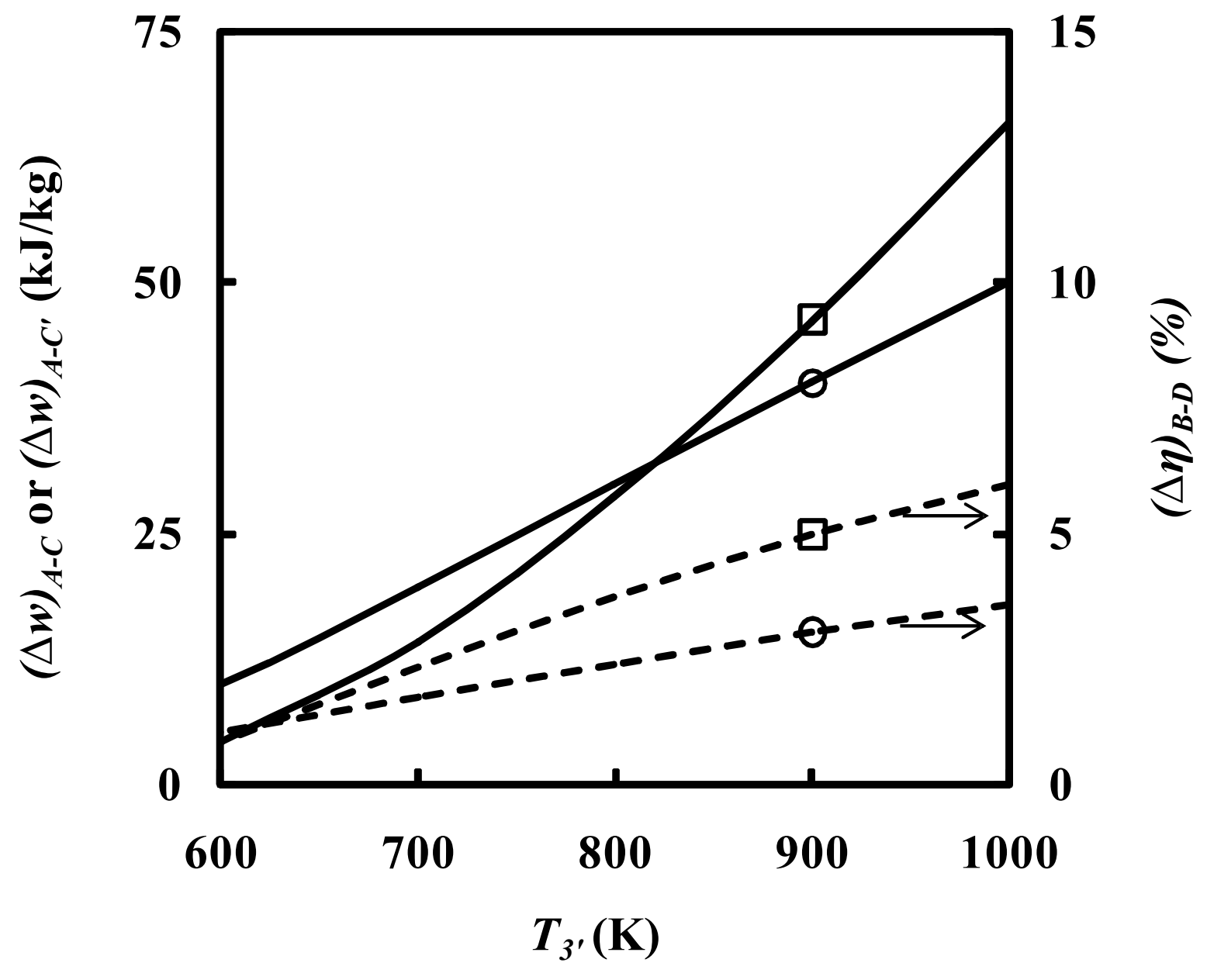

Fig. 5. $(\Delta w)_{A-C}$ or $(\Delta w)_{A-C^{\prime}}$ (possible change in load) and $(\Delta \eta)_{B-D}$ (corresponding change in efficiency) $v s T_{3^{\prime}}$ (source temperature). Legend: $-(\Delta w)_{A-C}$ or $(\Delta w)_{A-C}$, (left ordinate), - - $(\Delta \eta)_{B-D}($ right ordinate $), \square \mathrm{TN}-\mathrm{CO}_{2}$ cycle $\left(p_{I}=50 \mathrm{bar}\right), \circ \mathrm{S}-\mathrm{CO}_{2}$ cycle $\left(p_{I}=75 \mathrm{bar}\right)$ 


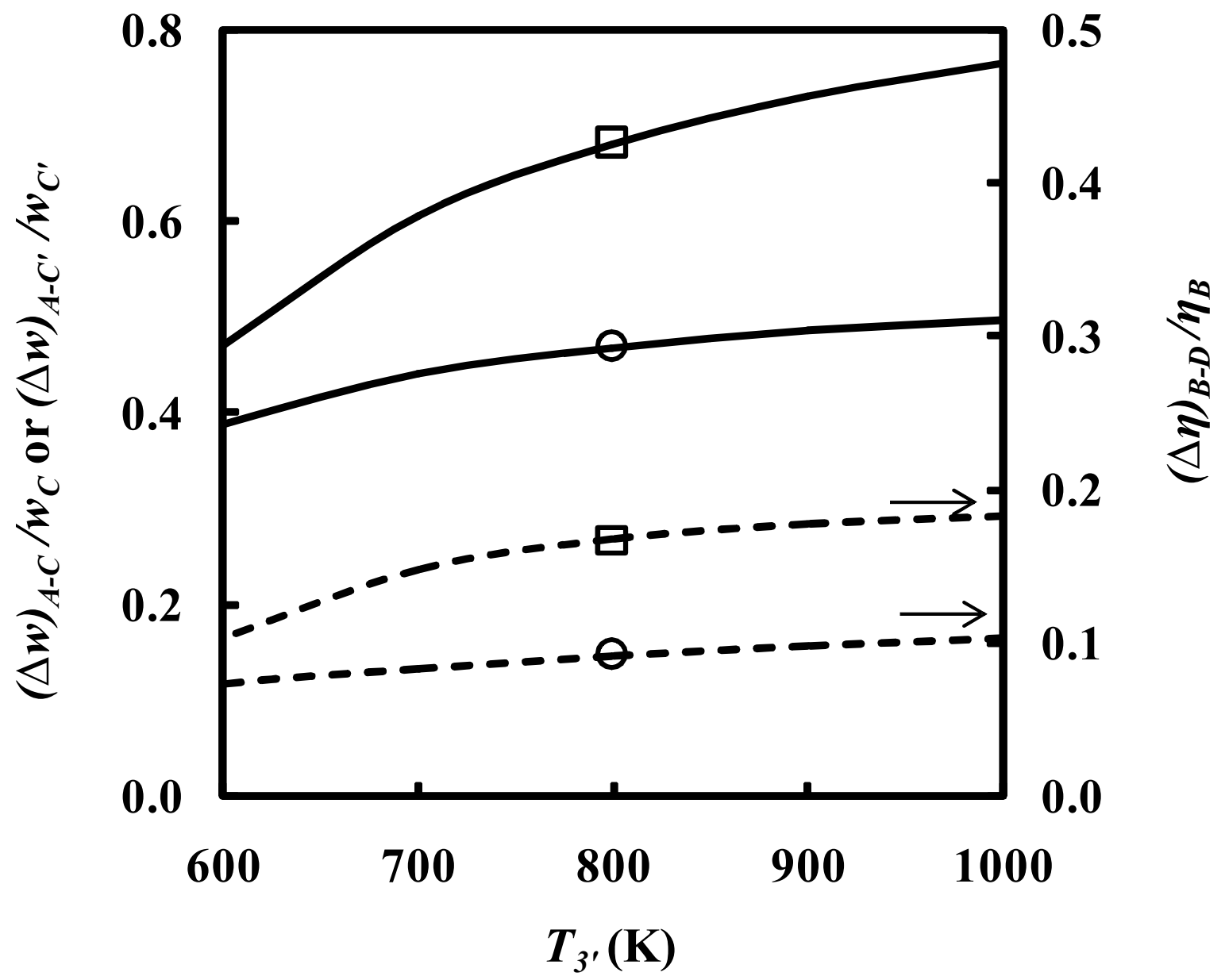

Fig. 6. $(\Delta w)_{A-C} / w_{C}$ or $(\Delta w)_{A-C} / w_{C}$ (possible fractional change in load) and $(\Delta \eta)_{B-D} / \eta_{B}$ (corresponding fractional change in efficiency) $v_{s} T_{3^{\prime}}$ (source temperature). Legend: $-(\Delta w)_{A-}$ $d w_{C}$ or $(\Delta w)_{A-C}{ }^{\prime} / w_{C},\left(\right.$ left ordinate),$---(\Delta \eta)_{B-D} / \eta_{B}$ (right ordinate), $\square \mathrm{TN}-\mathrm{CO}_{2}$ cycle $\left(p_{I}=50\right.$ bar), $\circ \mathrm{S}-\mathrm{CO}_{2}$ cycle $\left(p_{1}=75\right.$ bar $)$ 


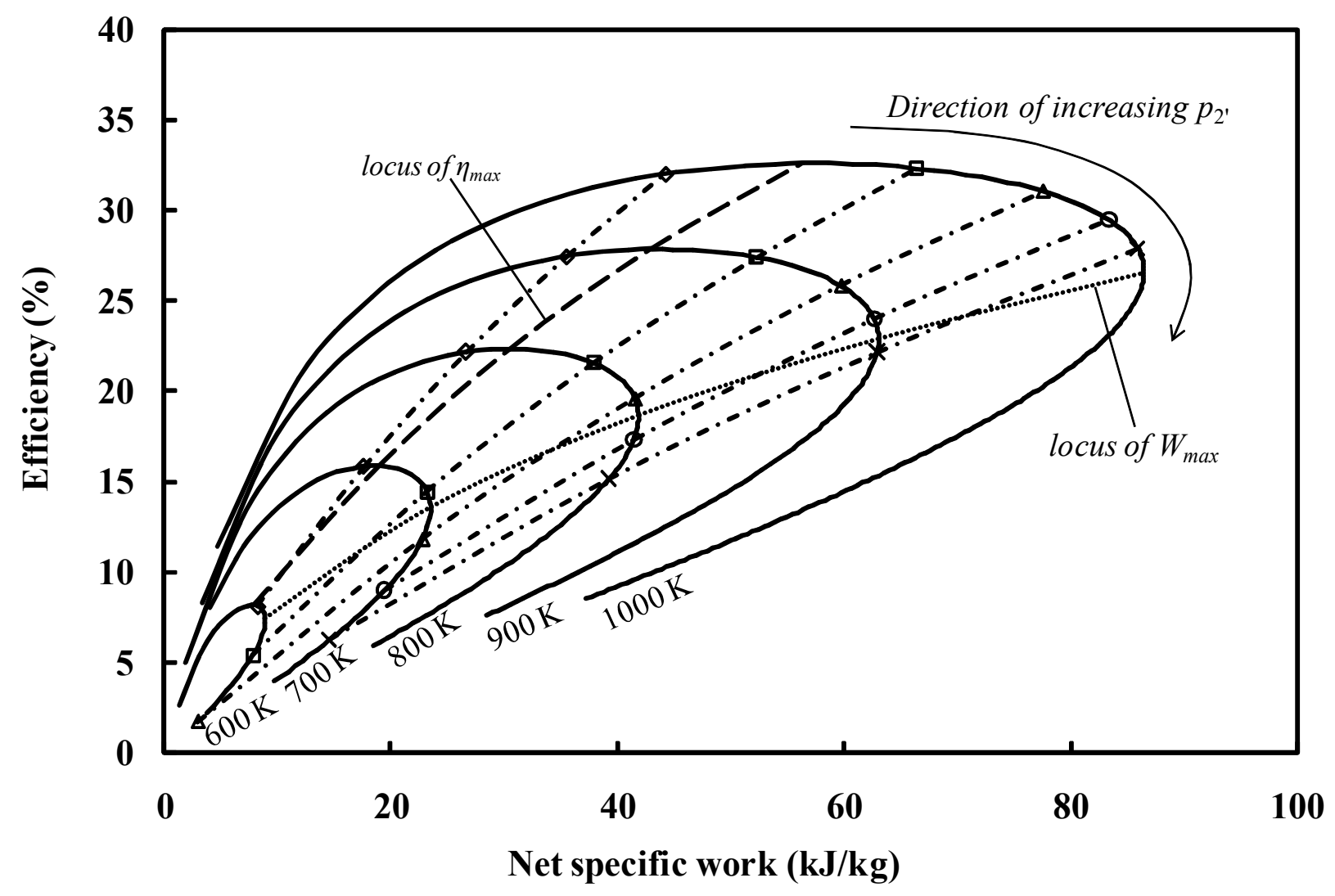

Fig. 7. Efficiency $v s$ net specific work for $\mathrm{TN}-\mathrm{CO}_{2}$ cycle. Legend: - isotherms, --- locus of $\eta_{\max }, \cdots \cdots \cdots \cdot$ locus of $W_{\max },-\cdot-\cdot-\operatorname{isobar}\left(p_{2^{\prime}}\right), \diamond p_{2^{\prime}}=100$ bar, $\square p_{2^{\prime}}=150$ bar, $\Delta p_{2^{\prime}}=200$ bar, $\circ p_{2^{\prime}}=250 \mathrm{bar}, \times p_{2^{\prime}}=300 \mathrm{bar}$ 


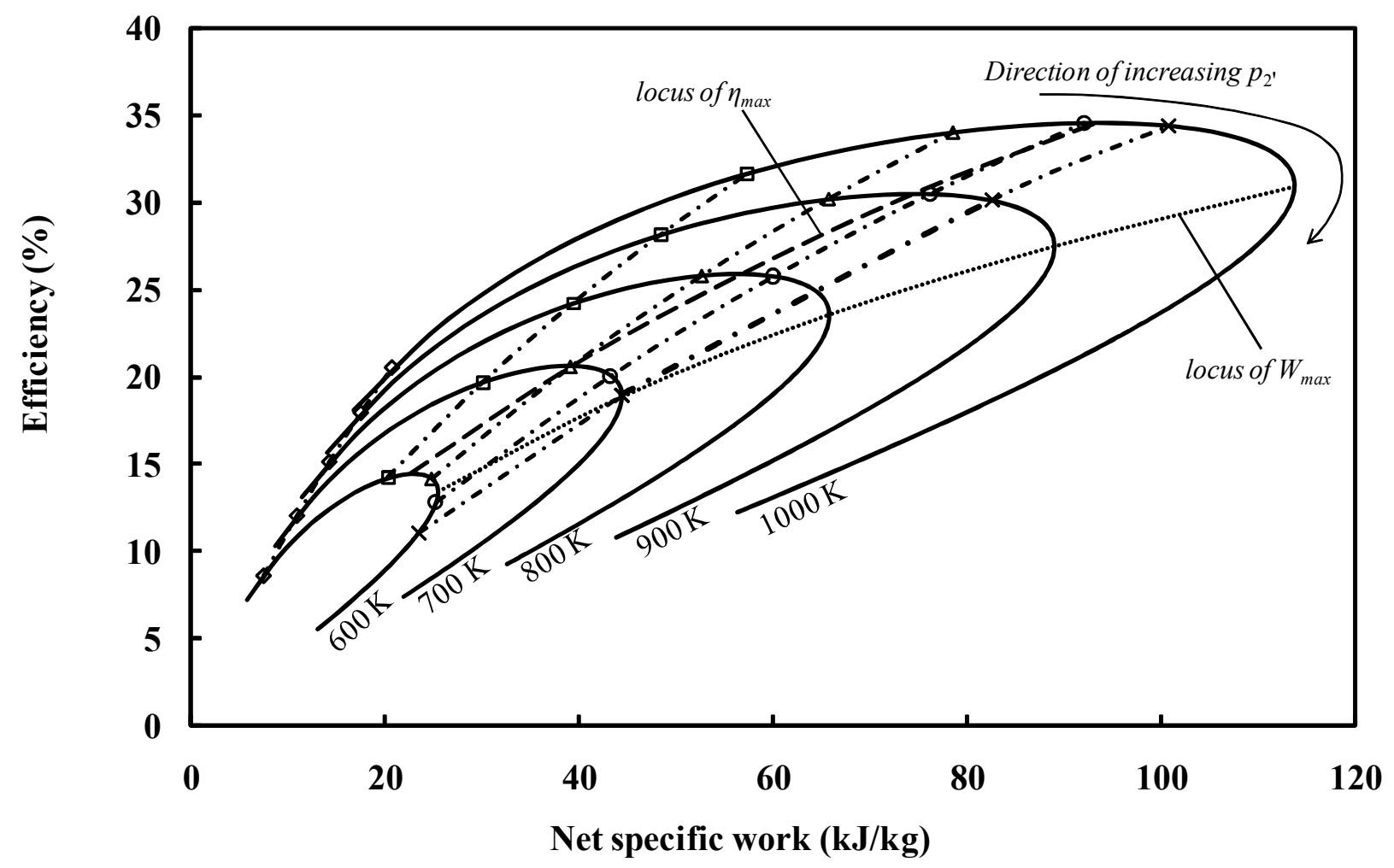

Fig. 8. Efficiency $v s$ net specific work for $\mathrm{S}-\mathrm{CO}_{2}$ cycle. Legend: - isotherms, - - - locus of $\eta_{\max }, \cdots \cdots \cdot \ldots$ locus of $w_{s p, \max },-\cdot-\cdot-$ isobar $\left(p_{2^{\prime}}\right), \diamond p_{2^{\prime}}=100$ bar, $\square p_{2^{\prime}}=150$ bar, $\Delta p_{2^{\prime}}=200$ bar, $\circ p_{2^{\prime}}=250 \mathrm{bar}, \times p_{2^{\prime}}=300 \mathrm{bar}$ 


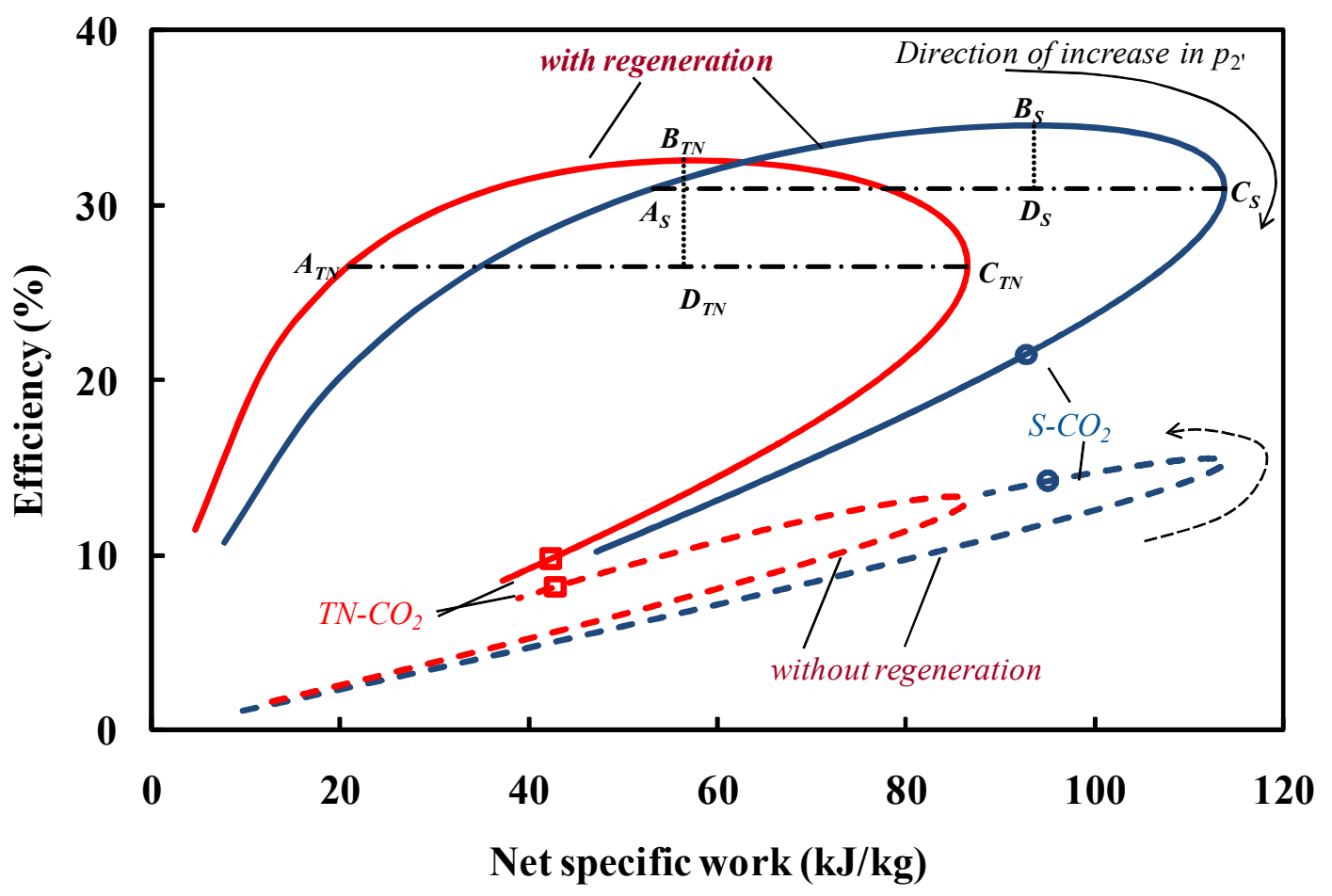

